\title{
Legal aspects of Blockchain's technology applicability for registration of intellectual rights
}

\author{
Lyudmila Novoselova ${ }^{1, *}$ and Elena Grin $^{1}$ \\ ${ }^{1}$ Intellectual Property Department of Kutafin Moscow State University (MSAL), 9 Sadovaya- \\ Kudrinskaya st., 125993, Moscow, Russia
}

\begin{abstract}
This article describes systems of accounting for the results of creative work, reveals possibilities for Blockchain's technology applicability for providing information about the protected results of intellectual activity and their inclusion in the turnover (commercialization). Legal mechanisms play an important role for successful implementation of the opportunities which form the basis of this technology. It also requires addressing the unjustified legal obstacles for applicability of the technology and, at the same time, deciding which includes the technology into established legal mechanisms. Authors analyze the main issues which may arise when including the results of intellectual activity into accounting systems based on Blockchain technologies.
\end{abstract}

\section{Introduction}

At present there are many being realized projects where Blockchain technology is used for deposition of author's works, attraction of investments for financing creation of creative result, conduct of transactions and etc.

The modern music industry demonstrates the largest concentration and breadth of usage of different projects based on Blockchain applicability [1].

For instance, users of Bittunes platform may have access to songs of independent artists by having payed use of the service with cryptocurrancy - bitcoins. Blockchain start-up Stem attracted funding in the amount of 4,5 million dollars. Users of the project were able to download their music and video on YouTube, Spotify, Apple Music, Soundcloud, monitor the use of their works and distribute their earnings fairly according to the programmed smart contracts [2].

Blockchain technologies are used for other objects such as photography (Mediachain start-up), artistic images of limited circulation (Swaincoin) $[3,4]$.

There are also some private projects connected with intellectual property rights management being realized in Russia. One of the examples is Soundchain platform which undertakes activities in the area of music industry [5]. IPChain is known to be one of the Russian Blockchain platforms created to facilitate communication between right holders and users and to increase transparency in intellectual rights` management administration.

\footnotetext{
* Corresponding author: helenkotenko@yandex.ru
} 


\section{Materials and Methods (Theoretical basis)}

Dialectic, formal-logical, functional and other general academic methods of research and also special legal methods such as comparative and formal legal.

\section{Results}

Use of Blockchain technologies to systematize results of intellectual activity may provide with storage, dissemination and transfer of information regarding the objects, right holders, management system of these rights, users and etc and, therefore, and will allow to exchange the existing databases devoted to objects of intellectual rights. Result's of intellectual activity systematization based on Blockchain technology complies with signs of modernity of technological provision ,safety, decentralization ,different levels of accessibility, absence of a third party for verification of transactions.

While systematizing the results of creative works use of Blockchain technologies shall allow to reduce costs for registration and maintenance of ongoing registers by organizations for collective exercise of copyright and related rights and other organizations, to unify the system and also to address unjustified mediation in this sphere.

In the future the register system of results of intellectual activity based on Blockchain technology shall ensure achievement of the most significant goal - creation of the unified global catalogue of intellectual activity results.

For that purpose it is necessary to:

- identify the common minimum requirements in respect of software for those platforms which are used for recording and commercialization of the results of intellectual activity;

- develop standards (terminology, the main procedures) of recording intellectual property accounting system;

- define model contracts in which one can enter by using such systems (including through the use a relevant software - "smart contract") ;

- provide with realization of "secure transactions" and also a new mechanism of arbitration which shall facilitate the resolution of disputable cases based on a consensus in real time.

The register based on Blockchain technology is able to link up technically to a real author of a photographic or musical work, in particular, while reposting. Moreover, the author shall definitely have the possibility to collect an outstanding reward.

The mandatory requirements for such a Register must be following: data on the work, including the year when the work was created, an album, format indication, in which the work is represented; tags; indication of a license, features of terms of use; a primary website where the work was posted on the website for the first time and other data (at the election of a right holder).

\section{Discussion}

Nowadays all proposed accounting systems, as a rule, are not connected with each other. For this reason the same object of intellectual rights may be included into a few registers with the equal conditions of order by an authorized person. A result may be a parallel purchase of the same inclusive right by different acquirers in different registers or the simultaneous acquisition of the exclusive right to use an object in the same scope of rights under the license agreement by different persons entitled under the agreement [6]. 
This problem can be solved technically by introducing the standards of the systems allowing their combination (at least for an automatic research of similar facilities). Nevertheless, this does not remove the need for legal solutions of possible collisions.

The problem of duplication of objects technically can be solved by verification of a digital identity. In the framework of intellectual rights obtaining of a digital identity can take place . Special digital codes such as DOI, ISWC, ISRC and others can be used.

It is possible to combine all the network profiles of a person into a single system. On the basis of the Blockchain, it is possible to use special user protocols with the storage of individual user's fingerprints of individual users through their ID or electronic business cards. Thus, change of information affected by a right holder shall lead to change of information in all the resources where it was registered ( for instance, through Emc Infocard; Emc TTS).

The platforms also can provide with recognition of plagiarism.

There is one more urgent problem for inclusive rights connected with the possibility of same time protection of the same result of intellectual activity with the use of different legal models. For example, a shape of the product can be saved as a copyright object in the form of an industrial design and also as a trademark. The balance of the rights to such "parallel objects" with the activation of the process of disposition of them lead to serious legal risks. The situation of inclusion in the turnover of individual protected parts of the work (including characters, titles, quotations) also requires regulation.

To solve the problems mentioned above, it is necessary to establish presumptions of the priority of rights for the person who was first to include the data in the accounting system when transferring the rights to the work as a whole and the rights to the protected part of the work in different systems. The holder of rights should be charged with the information obligation, secured by strict property sanctions, to report the inclusion of related objects in other registers.

Professor Melanie Swan points out that one of the first services to offer the services of notarization in a Blockchain is the Proof of Existence. For example, Monegraph project helps to protect images published on the Internet abroad. A user logins on a website, authorizes through an account of Twitter and indicates the URL of the image which the platform automatically processes and publishes the link in the requested format.

Then the platform provides the user with a code block which must be copied and pasted to the Namecoin's eWallet and adds the code block and the meaning, thus, only a one copy of a digital image is proved by the platform. The platform does not exclude further copy and dissemination of images but only the source file will be able to pass an investigation in the system [7].

\section{The issue of protection for the same result of intellectual activity with the use of different constructions}

Another pressing issue for inclusive rights is connected with the possibility of the same time protection for the same result of intellectual activity with the use of different legal constructions. For instance, a form of the product can be protected as a copyright object, an industrial design or as a trademark. At present, the correlation of rights to such "parallel objects" is complicated, and when activating of the process of disposition of them, may lead to serious legal risks.

No less problems arise when independent inclusion in the turnover of individual protected parts of the work (including characters, titles, quotes).

As a result, there may arise collisions of the rights of purchasers of such objects, the rights to which were acquired in various systems of the Blockchain. 
An algorithm is based on the approach mentioned earlier. For example, priority can be recognized for a person who has acquired an exclusive right to an object as a whole, or has concluded a license agreement with the most complete scope of rights.

Legislative decisions on the issue of priority when transferring the rights to the work in general and the rights to the protected part of the work in different systems may be different, but in any case, the rightholder should be charged with the informational obligation provided by strict property sanctions, to report on the inclusion of related objects to other registries.

The further use of digitized images in Blockchain may be solved by following decisions:

1) use of smart contracts;

2) duty of internal identification of users;

3) the possibility of interaction between different platforms among themselves (especially through the catalog of global music services and record labels);

4) making controversial decisions based on votes.

In the sphere of business industry Blockchain will be developing at least in 4 directions:

1) development of consortium platforms with the possibility of creating a global catalog;

2) preservation of privacy in ongoing transactions;

3) transaction validation;

4) maintenance of technological neutrality.

Thus, Blockchain technology is able to provide with a variety of solutions connected with creation of active systems of the account of intellectual rights. An active system of intellectual property accounting should be understood as a system that provides not only accounting for the results of intellectual activity and rights to them, but also directly used to conclude contracts for the use of these objects, their encumbrance, as well as reflecting changes in the rights holder. Use of Blockchain technology can fundamentally change the architecture of accounting systems and radically affect their functions.

The necessary conditions for development of registers based on Blockchain in Russia are not only thorough technical testing of vulnerabilities and stability of the system, but also the ability to work with other sites. Thus, the most popular websites such as Instagram, Facebook or Vkontakte where there is continuous file sharing could cooperate with such a project.

A register based on Blockchain is able to technically link to a real author of photographic or musical works, in particular, when posting. Moreover, the author shall definitely have a possibility to receive a reward due to. Therefore, it seems that the following data for the digitization of works should become mandatory requirements for such a register:

1) data on the work, including, but not limited to, the year of the creation of the work, an album, an indication of the format in which the work is provided, etc.

2) hashtags;

3) indication of the license, the specific conditions of use;

4) a primary website where the work was first posted;

5) directly digital reference work.

Legal mechanisms play an important role for successful realization of possibilities laying in technologies. On the one hand, it is necessary to overcome unfounded legal obstacles that exist today for using such technologies. On the other hand, there is a need for logical and conducive regulation leading to the exposure of useful capacities. And it's not just about governmental regulation, it's about supporting a system of self-regulation, alternative mechanisms for conflict prevention and resolution.

The wide use of Blockchain technology for the commercialization of intellectual property and the increase of the number of conflicts associated with the inclusion of objects in such systems put the issue of creating and implementing measures for the rapid prevention and elimination of intellectual property infringements on the agenda. The response to this need is the emergence of various new mechanisms of arbitration, which have not been 
systematized and studied yet. Their role should be fixed and correlated with the activities of the state judicial system in the short term. One option is to recognize their decisions as mandatory when following certain conditions, which should not be as strict as for arbitration courts.

Appeal of such decisions should be exercised in case of serious violations of the litigation procedure and also in other cases laid down by law. From the viewpoint of the judicial protection system, such decisions could be appealed exclusively in the Court of Intellectual Rights.

This report does not consider possible options for including objects of patent rights and means of individualization to registers based on Blockchain, as it requires the consideration of the correlation of private accounting systems with state`s registers for the accounting of relevant objects.

The task of creating accessible registers of works that are freely available, including the will of the author (free licenses, etc.) is closely connected with the creation of registers of protected intellectual property objects since the tendency of expanding the commercial use of works should be harmoniously combined with the tendency to provide free noncommercial access to works.

\section{Acknowledgements}

The study was conducted within the framework of the research project 17-33-00005 on the following topic: "Regulatory support of a system for the registration of rights to the results of intellectual activity in the digital sphere: development prospects".

\section{Reference}

1. Music On The Blockchain. Blockchain For Creative Industries Research Cluster (Middlesex University, 2016)

2. 10 projects based on Blockchain in the area of musical industry (2016) https://bits.media/news/blokcheyn-kak-revolyutsiya-v-muzykalnoy-industrii/

3. Mediachain, http://www.mediachain.io (2018)

4. Swincoin, http://swincoin.com (2018)

5. A. Abaev, Love to the music as investment, https://vc.ru/25112-soundchain-ico (2017)

6. A report by the UK Government Chief Scientific Adviser «Distributed Ledger Technology: beyond block chain», https:/www.gov.uk/government/uploads/system/uploads/attachment_data/file/492972/ gs-16-1-distributed-ledger-technology.pdf (2018)

7. M. Swan, Blockchain: Blueprint for a New Economy, 84 (2015) 